\title{
Evolution of Pt and Pd species in functionalized UiO-67
}

\section{metal-organic frameworks}

Aram L. Bugaev ${ }^{a *}$, Alina A. Skorynina ${ }^{a}$, Luca Braglia ${ }^{b}$, Kirill A. Lomachenko ${ }^{c}$, Alexander Guda $^{a}$, Andrea Lazzarini $^{d}$, Silvia Bordigad,e, Unni Olsbye ${ }^{d}$, Karl Petter Lillerud ${ }^{d}$, Alexander V. Soldatov ${ }^{a}$, Carlo Lamberti ${ }^{a, f}$

a The Smart Materials Research Institute, Southern Federal University, Sladkova 178/24, 344090 Rostov-onDon, Russia

${ }^{\mathrm{b}}$ CNR-IOM, TASC Laboratory, in Area Science Park, S.S.14, Km 163.5, I-34149, Trieste, Italy

${ }^{\mathrm{c}}$ European Synchrotron Radiation Facility, 71 avenue des Martyrs, CS 40220, 38043 Grenoble Cedex 9, France

${ }^{\mathrm{d}}$ Centre for Materials Science and Nanotechnology, Department of Chemistry, University of Oslo, Sem Saelands vei 26, 0371 Oslo, Norway

e Department of Chemistry, INSTM and NIS Centre, University of Turin, via G. Quarello 15, 10135 Turin, Italy

${ }_{\mathrm{f}}^{\mathrm{f}}$ Department of Physics, INSTM and CrisDi Interdepartmental Centre, University of Turin, via P. Giuria 1, 10125 Turin, Italy

*Corresponding author: abugaev@sfedu.ru 


\begin{abstract}
Functionalization of metal-organic frameworks (MOFs) with noble metals is a promising way for producing new versatile catalysts that will combine the outstanding porosity and specific surface area of MOFs with high catalytic activity of metals. Here, we present a comparative study of two metal-organic frameworks with UiO-67 topology, functionalized with palladium and platinum moieties. The initial structure of all studied samples contained palladium or platinum atoms grafted into $\mathrm{MCl}_{2}$ bpydc $(\mathrm{M}=\mathrm{Pd}, \mathrm{Pt})$ linkers of MOFs. The materials were further activated by heating in inert and $\mathrm{H}_{2}$-containing atmospheres. Both $\mathrm{Pd}$ - and Pt- functionalized materials exhibited high thermal stability upon heating in these atmospheres. The evolution of Pt and Pd species during the activation procedure was monitored by in situ time-resolved X-ray absorption near-edge structure (XANES) spectroscopy. We applied multivariate curve resolution alternating least squares (MCR-ALS) approach to XANES to unravel the intermediates which can be formed during the activation procedure. For UiO-67-Pd, only simple one-step transformation from $\mathrm{PdCl}_{2}$ bpydc to Pd nanoparticles (NPs) was observed. For UiO-67-Pt, two additional intermediate states were observed, which behave differently depending on the activation procedure. Theoretical calculation of XANES spectra allowed us to suggest the 3D-atomic structures corresponding to each of the pure spectra determined by MCR-ALS. In addition, reaction enthalpies for different possible reaction routs were calculated within a density functional theory approach. Based on the experimental and theoretical results showed that Pd nanoparticles (NPs) tend to be formed in UiO-67-Pd samples irrespective of the activation procedure, while either Pt NPs or isolated $\mathrm{Pt}^{\mathrm{II}}$ active sites, grafted in the MOF framework may be formed in UiO-67-Pt samples depending on the activation temperature and atmosphere.
\end{abstract}

Keywords: MOFs, XANES, multivariate curve resolution, UiO-67-Pt, UiO-67-Pd, metal nanoparticles

\title{
1. Introduction
}

Functionalization of metal-organic frameworks (MOFs) by metals is a promising way for producing new performing materials for catalytic applications [1-3]. Isostructural to the famous UiO-66 MOF [4-7], UiO-67 [4, 8] exhibits analogous high thermal, chemical and mechanical stabilities, and was shown to be a promising candidate for functionalization by incorporating metal ions into the structure by means of modified linkers. This goal has been achieved by substitution of a fraction (less than 10\%) of the standard biphenyl dicarboxylate (bpdc) linkers of UiO-67 by 2,2-bipyridine-5,5-dicarboxylic acid (bpydc) ones, with grafted Fe [9], Ni [10], Cu [11-13], 
$\mathrm{Ru}, \mathrm{Ir}, \mathrm{Re}$ [14], Rh [15], Pt [13, 16-20], and Pd [21-23]. The further treatment of such materials may result in formation of isolated single-atom active metal sites or reduction of metal ions with formation of nanoparticles (NPs) inside the cages of UiO-67. Understanding the evolution of local atomic structure around metal sites is necessary to design functional materials with required properties for specific applications.

X-ray absorption spectroscopy [24-26] was shown to be an efficient approach for investigation of the local structure inside MOFs [12, 19, 27-38]. Extended X-ray absorption fine structure (EXAFS) spectroscopy provides information on the coordination numbers and bond distances around the absorbing atom. X-ray absorption nearedge structure (XANES) probes the probes the lower unoccupied electronic states, which makes it sensitive to the local electronic structure, providing insights on the oxidation state and on the local symmetry of the metal center. With the development of new theoretical approaches, XANES spectra can be utilized to extract 3D local atomic structure including the information about light atoms [39-45], that may escape from being detected in EXAFS region.

In a number of previous works, we have performed a detailed EXAFS characterization of both Pt- [16, 19, 34] and Pd- [23, 46] functionalized metal-organic frameworks. However, the structure of the possible intermediates which may be present during the activation of functionalized UiO-67 samples remained unclear due to the high complexity of EXAFS analysis for multicomponent systems. In this work, we apply multivariate curve resolution alternating least squares (MCR-ALS) approach [47-49] to XANES spectra [50-57] collected in situ during different treatment procedures at $\mathrm{Pd} K$ - and $\mathrm{Pt} L_{3}$-edges, which allowed us to extract from the huge experimental datasets the spectra corresponding to pure species and obtain their evolution along the activation procedure. The obtained experimental spectra were complemented by theoretical XANES simulations and DFT-calculated atomic structures, whose relative energies were in agreement with experimental observations.

\section{Materials and Methods}

Functionalization of UiO-67 by palladium and platinum was achieved via substitution of 10\% standard bpdc linkers by $\mathrm{MCl}_{2}$ bpydc $(\mathrm{M}=\mathrm{Pd}, \mathrm{Pt})$ using the pre-made linker synthesis (PMLS) approach [16]. The synthesis procedure have been described in our previous works for both Pd [23] and Pt [19].

Experimental Pt $\boldsymbol{L}_{\mathbf{3}}$-edge X-ray absorption data was collected at BM01B beamline[58] (now moved to BM31 port) of ESRF. The sample was loaded inside a capillary connected to a remotely controlled gas panel. The 
temperature was controlled by a gas blower mounted below the capillary and calibrated using a thermocouple. In such environment, the samples were heated from room temperature (RT) to $300{ }^{\circ} \mathrm{C}$ with the ramp of $5{ }^{\circ} \mathrm{C} / \mathrm{min}$ in pure $\mathrm{He}, 3 \% \mathrm{H}_{2} / \mathrm{He}$, and $10 \% \mathrm{H}_{2} / \mathrm{He}$. The photon energy was scanned from 11.35 to $12.42 \mathrm{keV}$ by $\mathrm{Si}(111)$ double crystal monochromator operated in continuous scanning mode, which allowed collecting one spectrum in 4 minutes (i.e. one spectrum every $20^{\circ} \mathrm{C}$ ).

Experimental Pd $\boldsymbol{K}$-edge spectra presented in this paper were collected during three subsequent beamtimes. The first set of data was acquired at BM23 beamline [59] of ESRF. A pelletized sample was held in a microtomo cell [60] and was activated in a flow of $5 \% \mathrm{H}_{2} / \mathrm{He}(50 \mathrm{~mL} / \mathrm{min})$. The step-by-step mode of the monochromator allowed to collect one spectrum from 24.1 to $25.1 \mathrm{keV}$ every $40{ }^{\circ} \mathrm{C}$ of ramp. The second set of data was collected in a capillary at BM01B beamline using the similar sample environment as described above for Pt $L_{3}$-edge measurements. For the experiment, performed at BM23 beamline double-crystal fixed-exit Si(111) monochromator was employed. Harmonic rejection was done by two flat Pt-coated mirrors positioned at $2 \mathrm{mrad}$ angle. At BM01b beamline, the same type of the monochromator was employed, but the harmonics were rejected by detuning it down to $80 \%$ of the maximum intensity on top of the rocking curve. The samples were heated in a flow of $6 \% \mathrm{H}_{2} / \mathrm{He}$ from RT to $300{ }^{\circ} \mathrm{C}$ (at BM23 also higher temperatures up to $450{ }^{\circ} \mathrm{C}$ were applied) with the ramp of $5{ }^{\circ} \mathrm{C} / \mathrm{min}$ and XANES spectra were measured every $15^{\circ} \mathrm{C}$. The final experiment was performed at BM31 of ESRF using the same sample environment and applying the following treatment. The sample was first heated to the temperature at which the spectral changes start to occur and was then kept at this temperature for several hours. This procedure was repeated in a flow of $6 \% \mathrm{H}_{2} / \mathrm{He}$ and pure $\mathrm{He}$.

All spectra at both Pt $L_{3}$ - and Pd $K$-edges were collected in transmission mode with simultaneous measurements of Pt or Pd foils for energy calibration [61]. The mass flow controllers were adjusted to send ca. $1 \mathrm{~mL} / \mathrm{min}$ of the total flux per each $2 \mathrm{mg}$ of catalyst.

X-ray powder diffraction (XRPD) data for both Pt- and Pd- functionalized samples were collected in situ quasisimultaneously with X-ray absorption data during the experiment at BM01B to monitor the stability of UiO-67 crystal structure. The optic hutch of the beamline is equipped with a double set of monochromators and mirrors that allows a plug-and-play switch between X-ray absorption and diffraction set-ups in less than one minute [62, 63]. The photon wavelength $\lambda=0.51353(1)$ was selected by $\operatorname{Si}(111)$ channel-cut monochromator. The scattered signal was registered by Dexela CMOS flat plate detector in the $2 \theta$-range from 2 to $32^{\circ}$. The LaB 6 and Si NIST 
references were measured to calibrate the geometrical parameters of the setup. The 2D patterns were integrated in PyFAI [64] and refined in Jana2006 code [65]. See Supporting Information for the XRPD data.

XANES analysis was performed in MCR-ALS code [47-49] using the normalized X-ray absorption spectra. In this approach, XANES spectra are represented by matrix $\mathbf{D}$ of size $m \times n$, where $m$ is the number of spectra in the dataset and $n$ is the number of energy points. This matrix is decomposed as $\mathbf{D}=\mathbf{C S}^{\mathrm{T}}+\mathbf{E}$, where $\mathbf{C}$ with size $m \times k$ is the concentration profiles of $k$ pure components from matrix $\mathbf{S}(n \times k)$, and $\mathbf{E}(m \times n)$ is the error matrix. The energy ranges were limited to $11.4-11.8$ and 24.2 - $24.6 \mathrm{keV}$ for Pt $L_{3}$ - and $\mathrm{Pd} K$-edges, respectively. The optimal number of components was chosen based on a logarithmic plot of the explained variance as function of the component's number obtained during principle component analysis (PCA) [66-70]. The non-negativity of both concentrations and spectra, and closure of spectra were used as additional constrains during the ALS procedure. The spectra extracted from the experimental datasets were compared with theoretically calculated relativistic XANES spectra obtained in the accelerated version of FDMNES code [39, 40, 71] within a full potential finite difference method (cluster radius $R=7 \AA$ ).

Atomic models used for XANES calculation were initially optimized in VASP 5.3 code [72-74] with PBE exchange-correlation potential [75]. Initial structures were taken from the crystallographic data for UiO-67-Pd [23]. Then, only single linker was left and was located in the center of cubic cell with $a=20 \AA$. The whole series of the optimized atomic structures is described in Section 3 and includes the initial $\mathrm{MCl}_{2}$ bpydc linker $(\mathrm{M}=\mathrm{Pd}$, $\mathrm{Pt}$ ) and its modifications (e.g. removal of Cl-ligands, substitution of Cl-ligands by hydrogen, detachment of metal from the linker and formation of metal nanoparticles). All calculations were performed using a single $k$-point with the plane-wave basis cutoff at $400 \mathrm{eV}$ and the Gaussian broadening of energy levels by $0.1 \mathrm{eV}$. The atomic positions were optimized until all forces were reduced below $10^{-2} \mathrm{eV} / \AA ̊$ respectively. To estimate the energies, required to modify the local structure around $\mathrm{Pd}$ and $\mathrm{Pt}$, free energies of all the structures including $\operatorname{single~} \mathrm{H}_{2}, \mathrm{Cl}_{2}$ and $\mathrm{HCl}$ molecules were calculated. For energy calculation, the cutoff value for the plane-wave set was taken at $550 \mathrm{eV}$ and the convergence criterion for SCF cycles was set to $10^{-5} \mathrm{eV}$.

\section{Results and Discussion}

The evolution of experimental data presented in Figure 1 evidences the sensitivity of XANES spectra to the changes of local structure around Pt- (part a) and Pd- (part b) functionalized samples during the heating process. The standard fingerprint analysis, based on the visual similarity of the starting and final spectra with those of 
$\mathrm{MCl}_{2}$ bpydc references and metal foils, allowed us to interpret the observed evolution as a transformation from the initial state (where metal is grafted into the structure of the linker) to a metallic state (where metal atoms are detached from the linker and form metal NPs) [19, 23]. However, the fingerprint analysis does not provide complete information on the system due to several reasons. The first reason is that the observed experimental spectra may not correspond to any of the known references. This is the case of UiO-67-Pt sample activation in the inert atmosphere (see the inset in Figure 1a, dashed line). Secondly fingerprint analysis does not provide quantitative analysis of the mixtures of several different local surroundings around absorbing atom. This fact complicates the determination of intermediates which were formed during the activation procedure.
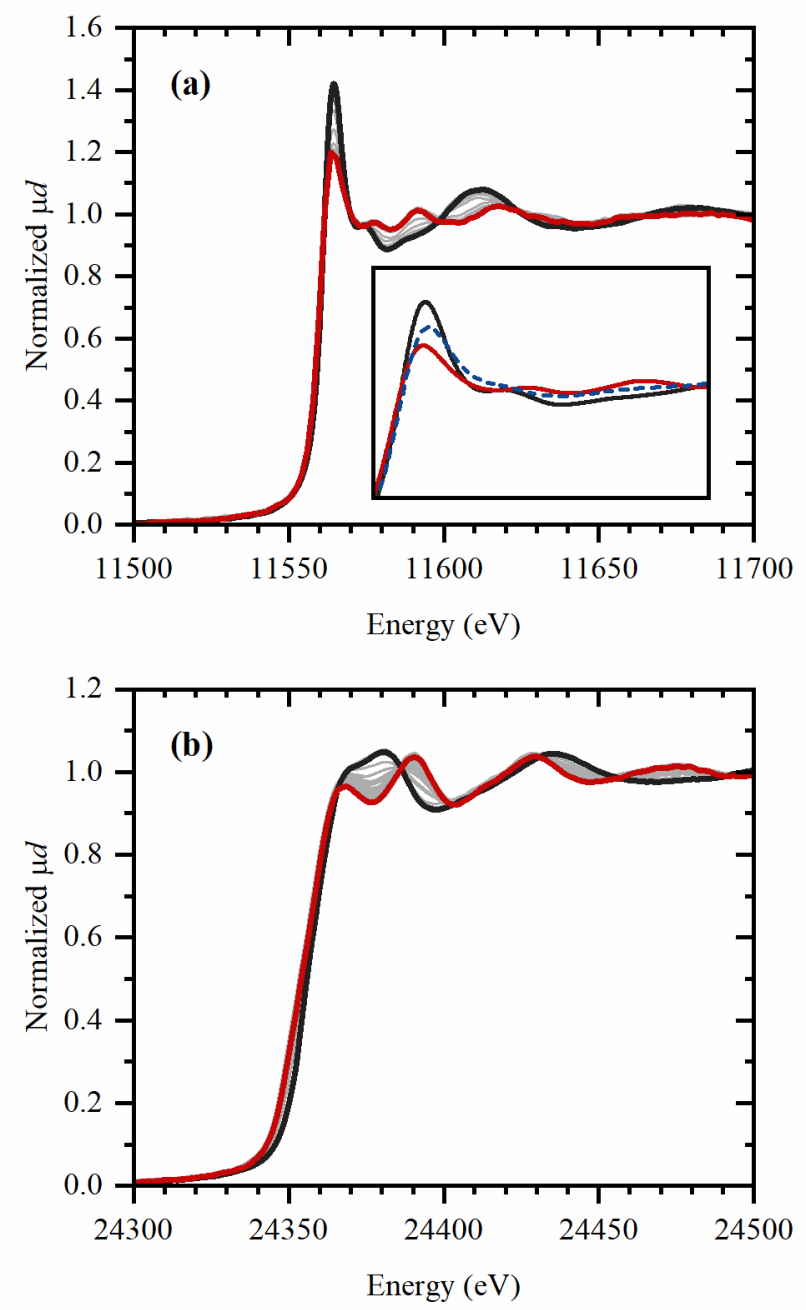
Figure 1. Evolution of experimental Pt $L_{3}$-edge (a) and Pd $K$-edge (b) XANES spectra during the heating of UiO-67 functionalized with $\mathrm{Pt}$ and Pd, from RT (black spectra) to $300{ }^{\circ} \mathrm{C}$ (red spectra). The utilized gas feed contained $10 \%$ and $6 \% \mathrm{H}_{2}$ in $\mathrm{He}$ for Pt- and Pdsamples, respectively. The inset in part (a) shows the enlarged region of the first peak of Pt $L_{3}$-edge XANES taken at RT (black) and after activation at $300{ }^{\circ} \mathrm{C}$ in $10 \% \mathrm{H}_{2} / \mathrm{He}$ (red) and pure $\mathrm{He}$ (dashed blue).

To overcome the mentioned issues, we have applied MCR-ALS approach, which allows the determination of the spectra corresponding to pure species without the necessity of having reference spectra. The analysis contained several steps. At the first step, PCA is performed to determine the number of statistically relevant components in the whole experimental dataset. For Pt $L_{3}$-edge, the three series of data collected during the activation in 0,3 and $10 \% \mathrm{H}_{2} / \mathrm{He}$ were analyzed simultaneously. The 5 most relevant abstract components determined by PCA are shown in Figure 2a-e. Each subsequent component is characterized by a decreasing amplitude which is finally getting close to the noise level at the $5^{\text {th }}$ component (part e). The variance explained by each of the component plotted in a logarithmic scale also reveals a characteristic change in the slope at the $n=4$. This means that the four independent components should be used to reproduce the whole experimental dataset, while the improvement of reconstruction by addition of more than 4 components is negligible. Indeed, the shape of the fifth component (Figure 2e) does not contain any structurally relevant signal and is clearly composed by noise only. In addition, the independent proof of the existence of four different components is that after transformation (vide infra) they produce four XANES spectra with relevant differences in spectral features (Figure 3a).
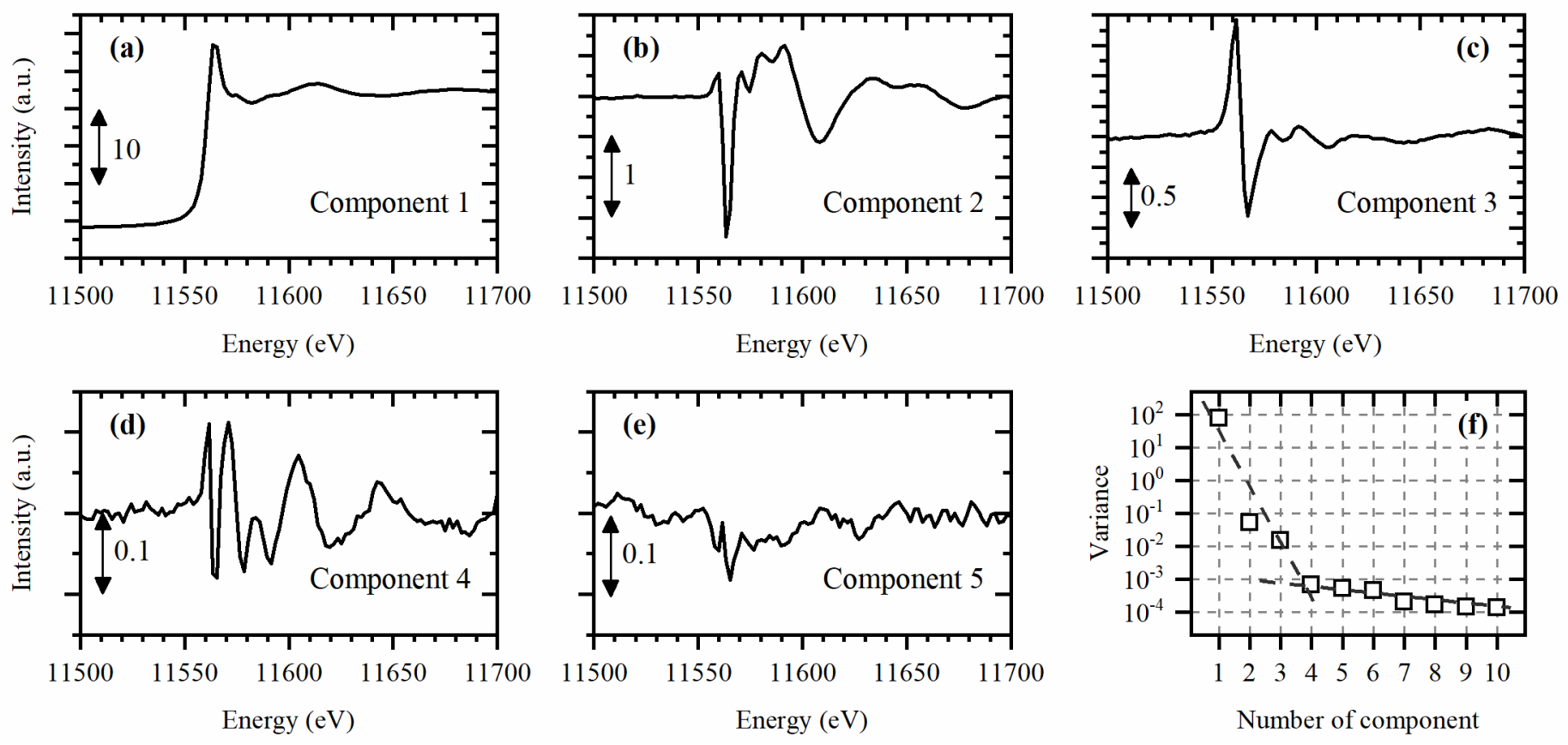
Figure 2. The first five PCA components (a-e) and the variance explained by each of the component plotted in a logarithmic scale. The analysis refers to the Pt $L_{3}$-edge XANES spectra reported in Figure 1a.

At the second step, the MCR-ALS routine [47] is applied to perform a transformation of the abstract PCA components into physically meaningful spectra (Figure 3a) that can reconstruct the whole set of experimental data, providing the concentration profiles shown in Figure 3b-d for three different activation experiments. The preliminary identification of the obtained pure spectra can be already done based on their spectral features and behavior during the activation procedure. The first spectrum (dark grey) is maximal for the initial UiO-67-Pt material in inert atmosphere and completely disappears at $300{ }^{\circ} \mathrm{C}$ under all activation conditions $(0,3$, and $10 \%$ $\mathrm{H}_{2}$ in He; Figure $3 b-\mathrm{d}$ ). Therefore, this spectrum should correspond to $\mathrm{Pt}^{\mathrm{II}}$ state in $\mathrm{PtCl}_{2}$ bpydc linker. The second spectrum (red), that visually resembles the spectrum of Pt NPs with characteristic shape and edge shifted to lower energy with respect to the initial state, is formed at $300{ }^{\circ} \mathrm{C}$ under all activation conditions and its concentration reaches the unity for the sample treated in $10 \% \mathrm{H}_{2} / \mathrm{He}$ (Figure $3 \mathrm{~d}$ ). Formation of this spectrum takes place under all activation conditions, starting already at ca. $200{ }^{\circ} \mathrm{C}$ in presence of $\mathrm{H}_{2}$, but only at ca. $300{ }^{\circ} \mathrm{C}$ in pure He (Figure $3 b)$. In the latter case, the new component (blue spectrum) is forming starting at ca. $220^{\circ} \mathrm{C}$, reaching its maximum around $270{ }^{\circ} \mathrm{C}$ and then coexisting with a small fraction of Pt NPs (red spectrum) for 1 hour at $300{ }^{\circ} \mathrm{C}$. The position of the white line in this peak is shifted towards higher energies. It is important to note that although small amounts of this component are present in the series of spectra collected in $\mathrm{H}_{2}$, only the dataset collected in He makes this component statistically relevant. Finally, the fourth spectrum (green) is present under all activation conditions up to $250{ }^{\circ} \mathrm{C}$. This spectrum is similar to the first one (dark grey) but has a slightly lower intensity of the white line and the spectral features are shifted towards lower energies (e.g. peak $\mathrm{C}$ at $\sim 11610 \mathrm{eV}$ is shifted to the left by $3 \mathrm{eV}$ ), which is an indication of the increasing interatomic distances. A considerable growth of the fraction of this spectrum by $40 \%$ is observed already at RT if the sample is exposed to $\mathrm{H}_{2}$ (Figure $3 \mathrm{c}-\mathrm{d}$ ). For Pd $K$-edge data only two components were determined (Figure 4). The assignment of the pure spectra (Figure 4a) and their concentration profiles (Figure 4b,c) is quite straightforward and correlates with the previous works [23, 46]. In the initial material, $\mathrm{Pd}^{\mathrm{II}}$ ions were located in $\mathrm{PdCl}_{2}$ bpydc linkers, and were then reduced to Pd NPs. In presence of $\mathrm{H}_{2}$, the reduction starts at ca. $200^{\circ} \mathrm{C}$, while in inert atmosphere the process starts higher temperatures, closer to $300^{\circ} \mathrm{C}$. 

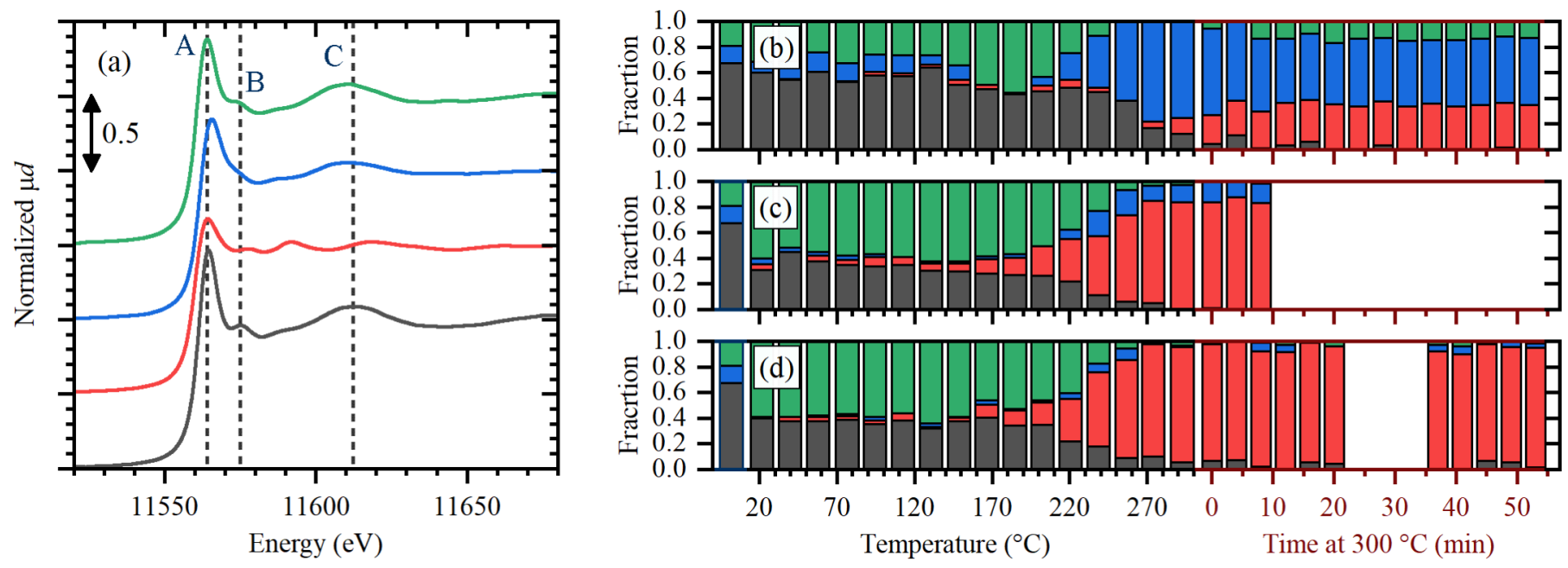

Figure 3. XANES spectra (a) determined by MCR-ALS for the whole set of experimental Pt $L_{3}$-edge XANES spectra, and their concentration profiles during the activation of UiO-67-Pt in $\mathrm{He}(\mathrm{b})$, in $3 \% \mathrm{H}_{2} / \mathrm{He}(\mathrm{c})$ and in $10 \% \mathrm{H}_{2} / \mathrm{He}(\mathrm{d})$. The same color was used to plot the spectra (a) and their fractions (b-d). For clarity, the spectra in part (a) are shifted vertically. The starting point below $t=20{ }^{\circ} \mathrm{C}$ in parts (b-d) with the abscissa colored in dark blue represents the initial UiO-67-Pt material in He at RT. The black colored part of abscissa corresponds to the heating process from RT to $300{ }^{\circ} \mathrm{C}$; finally, the region corresponding to the sample kept at $300{ }^{\circ} \mathrm{C}$ is highlighted by dark-red abscissa line. In parts (b-d), the areas left in white color correspond to moments where the spectra were not collected due to experimental problems.
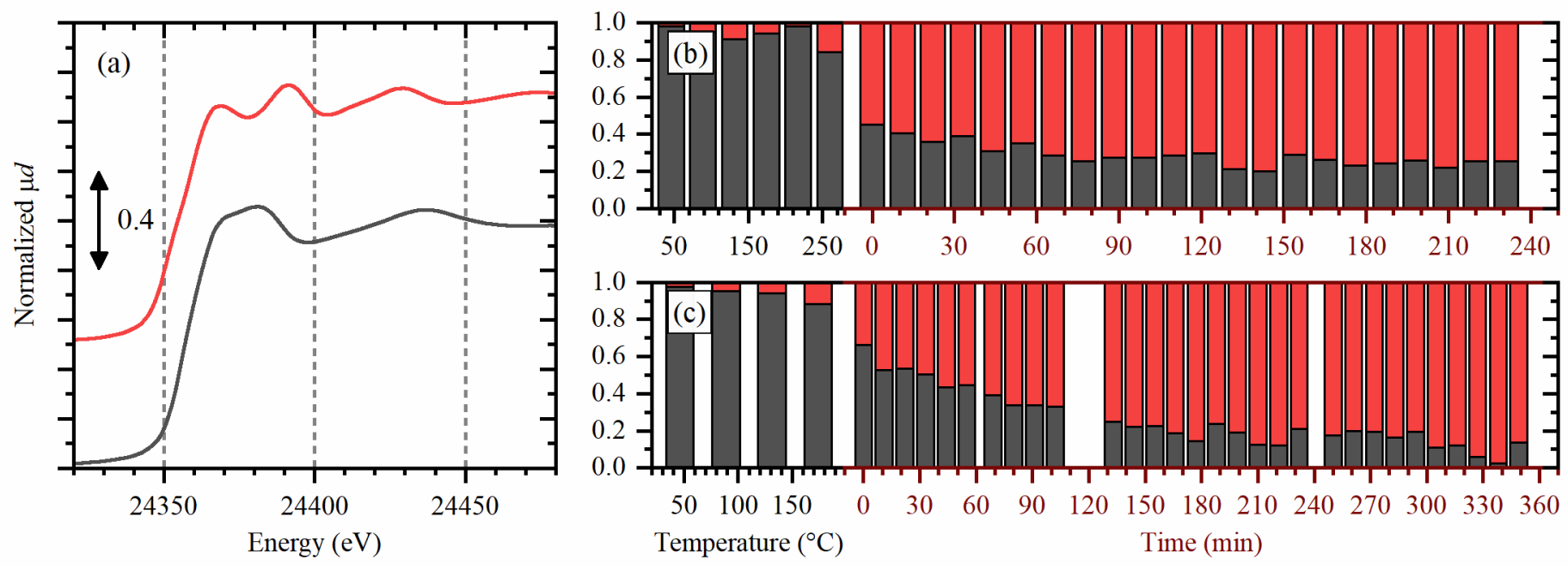

Figure 4. XANES spectra (a) determined by MCR-ALS for the whole set of experimental Pd $K$-edge XANES spectra, and concentration profiles obtained by reconstruction of the spectra collected during the heating of UiO-67-Pd sample in $\mathrm{He}(\mathrm{b})$ and in $6 \% \mathrm{H}_{2} / \mathrm{He}(\mathrm{c})$. The black colored part of abscissa corresponds to the ramp region, while the dark-red part of abscissa shows the time the catalyst spent at $300{ }^{\circ} \mathrm{C}$ in pure $\mathrm{He}\left(\right.$ b) and at $215^{\circ} \mathrm{C}$ in $6 \% \mathrm{H}_{2} / \mathrm{He}(\mathrm{c})$. In parts (b-c), the areas left in white color correspond to moments where the spectra were not collected due to experimental problems. 
To prove the correct assignment of the observed spectra, we have calculated theoretical XANES spectra using a set of DFT-optimized atomic structures presented in Figure 5. These included a standard $\mathrm{MCl}_{2}$ bpydc $(\mathrm{M}=\mathrm{Pd}$, Pt) linker (0), a linker with two chlorines substituted by hydrogen atoms with formation of $\mathrm{Cl}_{2}$ molecule (1), one chlorine substituted by hydrogen atom with formation of $\mathrm{HCl}$ molecule (2), detachment of two chlorines with formation of two $\mathrm{HCl}$ molecules (3), detachment of $\mathrm{MCl}_{2}$ fragment from the linker with its substitution by two hydrogens bond to nitrogen atoms of the linker (4), simple detachment of $\mathrm{MCl}_{2}$ fragment (5), and detachment of chlorines with formation of $\mathrm{Cl}_{2}$ molecule (6). The routes (1) - (4) involve $\mathrm{H}_{2}$ molecule, while the (5) and (6) do not, which resembles the thermal treatment of the sample in pure He.

(1)

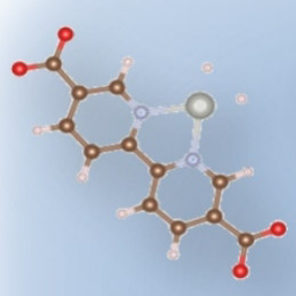

(3)

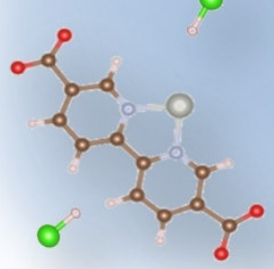

(2)

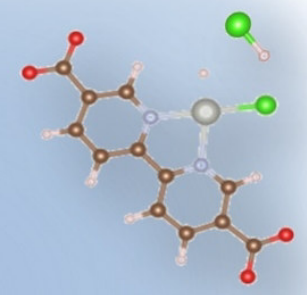

(4)

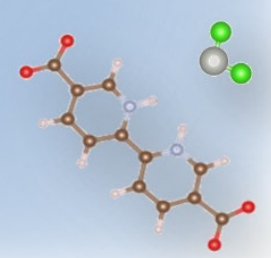

$(0)$

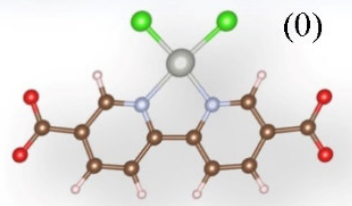

(5)

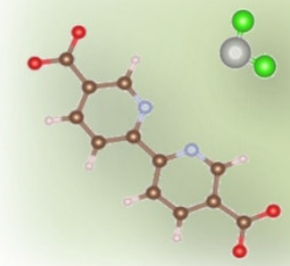

(6)

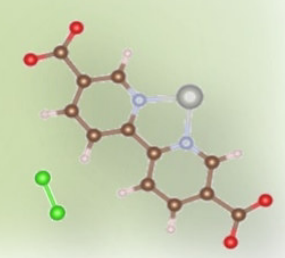

Figure 5. A set of atomic structures used for calculations of XANES spectra (Figure 6) and decomposition energies (Table 1). Color code: metal (Pt or Pd, gray), N (green), C (brown), H (white), O (red). 
Table 1. Calculated energy differences $\Delta E$ in $\mathrm{eV}$ between the starting $\mathrm{MCl}_{2}$ bpydc $(\mathrm{M}=\mathrm{Pd}, \mathrm{Pt})$ and the structures presented in Figure 5 .

\begin{tabular}{lcc} 
& Pd & Pt \\
\hline$(0) \rightarrow(1)$ & 2.70 & 2.62 \\
$(0) \rightarrow(2)$ & 0.31 & 0.19 \\
$(0) \rightarrow(3)$ & 0.79 & 1.94 \\
$(0) \rightarrow(4)$ & -2.38 & 1.66 \\
$(0) \rightarrow(5)$ & 0.04 & 4.08 \\
$(0) \rightarrow(6)$ & 2.65 & 3.79
\end{tabular}
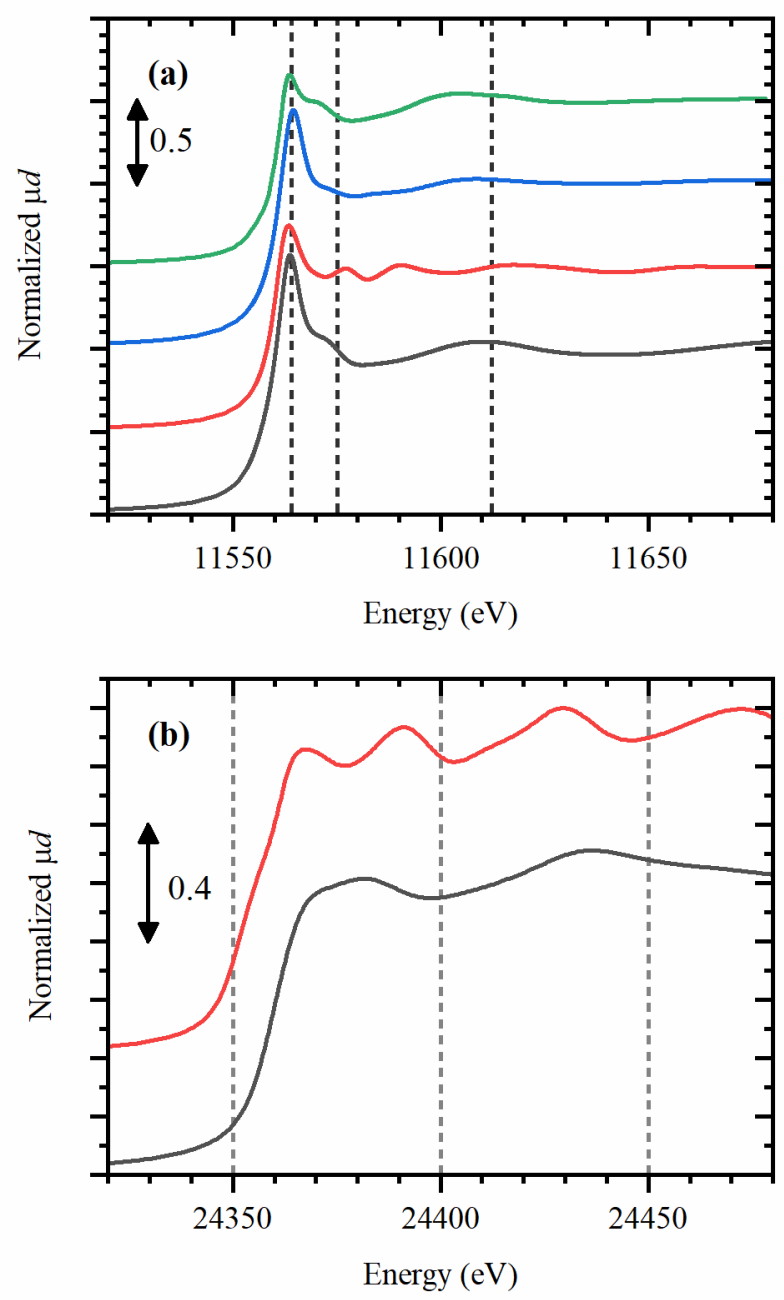

Figure 6. (a) Theoretical Pt $L_{3}$-edge XANES computed for clusters (0), (6) and (2) (grey, blue and green lines, respectively) reported in Figure 5, and for $f c c$ Pt cluster of 141 atoms (red line). (b)Theoretical Pd $K$-edge computed for cluster (0) (grey line) and for $f c c \mathrm{Pd}$ cluster of 141 atoms (red line). 
The calculated energy differences between the starting $\mathrm{MCl}_{2}$ bpydc linker $(0)$ and each of the structures from the Figure 5 are presented in Table 1. The values were obtained as the difference between the energy of the initial $\mathrm{MCl}_{2}$ bpydc linker (or the sum of this energy with the energy of $\mathrm{H}_{2}$ molecule) and the sum of the energies of the resulting parts. It should be noted that these calculations were performed on the isolated linkers and do not take into account the possible effect from the crystalline structure of UiO-67. However, the relative comparison of the obtained values is in a good agreement with experimental observations. In particular, for $\mathrm{PdCl}_{2}$ bpydc the most probable routes involve detachment of $\mathrm{PdCl}_{2}$ species from the linker, $(0) \rightarrow(4)$ and $(0) \rightarrow(5)$ reactions in Figure 5, which correlates with the fact that Pd NPs were directly formed in both $\mathrm{H}_{2} / \mathrm{He}$ and pure He flows (Figure 4). The fact that in pure He this process occurred at higher temperatures than in $\mathrm{H}_{2}$ containing flow (Figure 4b,c) is in agreement with the higher energy of route $(0) \rightarrow(5)$ with respect to route $(0) \rightarrow(4)$. For $\mathrm{PtCl}_{2}$ bpydc in presence of $\mathrm{H}_{2}$ the most probable route is a substitution of one chlorine atom by hydrogen atom with formation of $\mathrm{HCl}$ molecule, $(0) \rightarrow(2)$, which may explain the grows of the fraction of the green spectrum in Figure $3 \mathrm{c}, \mathrm{d}$ below 200 ${ }^{\circ} \mathrm{C}$. The second possible route favored in presence of $\mathrm{H}_{2}$ is the detachment of $\mathrm{PtCl}_{2}$ from the linker with attachment of two hydrogen atoms to the nitrogen atoms of the linker, (0) $\rightarrow$ (4) route. In contrast to Pd case, the most probable route in the absence of $\mathrm{H}_{2}$ is the detachment of Cl-ligands leaving unsaturated Pt- sites [16]. The theoretical XANES spectra (Figure 6) calculated according to the discussed structures are in good agreement with experimental XANES spectra extracted from the experimental data by MCR-ALS (Figure 3a and Figure 4a), except for the green spectrum in Figure 6a, where the changes with respect to the initial one (dark grey) are stronger than in the corresponding spectra from MCR-ALS (Figure 3a). In addition to comparison of theoretical and experimental XANES spectra, the facts of $\mathrm{Cl}$ detachment from Pt in inert atmosphere and of formation of Pt

NPs in hydrogen were independently confirm by EXAFS analysis of the pure spectra obtained by application of MCR-ALS to the full EXAFS spectra (See Section S3 of the Supporting Information and Figures S3-S5).

\section{Conclusions}

We have performed a detailed XANES investigation of Pt- and Pd- functionalized UiO-67 MOF which allowed to reveal the evolution of Pt- and Pd- species under different treatment conditions. Only one step transformation from $\mathrm{PdCl}_{2}$ bpydc to Pd NPs was observed for UiO-67-Pd samples, irrespective of the treatment conditions; while for UiO-67-Pt, four different structures, including two intermediates were determined. Application of MCR-ALS approach allowed us to extract the $\mathrm{Pd} K$ - and $\mathrm{Pt} L_{3^{-}}$XANES spectra corresponding to pure Pd- and Pt-species and to suggest their simple interpretation based on their spectral changes supported by the theoretical calculations of 
XANES and concentration profiles. The observed experimental trends are in good agreement with the theoretical calculations of energies required to induce the modification in the local structure of metal atoms grafted into the linkers in presence and in absence of hydrogen. In particular, the temperature range from 200 to $300{ }^{\circ} \mathrm{C}$ was shown to provide formation of isolated Pt-sites in the inert flow. While formation of Pt NPs is favored at temperatures above $300^{\circ} \mathrm{C}$ and in presence of $\mathrm{H}_{2}$. At the same time, Pd-functionalized samples do not possess such versatility due to energetically favorable process of direct detachment of the $\mathrm{PdCl}_{2}$ species from the linker and Pd NPs tend to be formed for both inert and $\mathrm{H}_{2}$-containing flows at lower temperatures than Pt samples.

\section{Acknowledgments}

A.L.B. and A.A.S. acknowledge Russian Science Foundation project No. 18-73-00189 for funding the research. A.L., U.O. and K.P.L. acknowledge the Research Council of Norway project 250795. We are indebted to Elisa Borfecchia and Andrea Martini for fruitful discussion. We thank Suresh Gatla, Olivier Mathon and Sakura Pascarelli for their assistance during experiment at BM23. We also thank Vladimir Dmitriev, Herman Emerich, Wouter van Beek and Michela Brunelli for the friendly and competent support during the experiments performed at BM01B and BM31 beamlines of the ESRF.

\section{Funding}

Russian Science Foundation (grant No. 18-73-00189 to A.L.B. and A.A.S.).

\section{References}

[1] S.L. Qiu, G.S. Zhu, Molecular engineering for synthesizing novel structures of metal-organic frameworks with multifunctional properties, Coord. Chem. Rev., 253 (2009) 2891-2911. [2] Z. Wang, S.M. Cohen, Postsynthetic modification of metal-organic-frameworks, Chem. Soc. Rev., 38 (2009) 1315-1329.

[3] K.K. Tanabe, S.M. Cohen, Postsynthetic modification of metal-organic frameworks - A progress report, Chem. Soc. Rev., 40 (2011) 498-519.

[4] J.H. Cavka, S. Jakobsen, U. Olsbye, N. Guillou, C. Lamberti, S. Bordiga, K.P. Lillerud, A new zirconium inorganic building brick forming metal organic frameworks with exceptional stability, J. Am. Chem. Soc., 130 (2008) 13850-13851.

[5] L. Valenzano, B. Civalleri, S. Chavan, S. Bordiga, M.H. Nilsen, S. Jakobsen, K.P. Lillerud, C. Lamberti, Disclosing the complex structure of UiO-66 MOF: a synergic combination of experiment and theory, Chem. Mater., 23 (2011) 1700-1718. 
[6] G.C. Shearer, S. Chavan, J. Ethiraj, J.G. Vitillo, S. Svelle, U. Olsbye, C. Lamberti, S. Bordiga, K.P. Lillerud, Tuned to perfection: Ironing out the defects in metal-organic framework UiO-66, Chem. Mater., 26 (2014) 4068-4071.

[7] S. Øien, D. Wragg, H. Reinsch, S. Svelle, S. Bordiga, C. Lamberti, K.P. Lillerud, Detailed structure analysis of atomic positions and defects in zirconium metal-organic frameworks, Cryst. Growth Des., 14 (2014) 5370-5372.

[8] S. Chavan, J.G. Vitillo, D. Gianolio, O. Zavorotynska, B. Civalleri, S. Jakobsen, M.H. Nilsen, L. Valenzano, C. Lamberti, K.P. Lillerud, S. Bordiga, $\mathrm{H}_{2}$ storage in isostructural UiO-67 and UiO-66 MOFs, Phys. Chem. Chem. Phys., 14 (2012) 1614-1626.

[9] N.C. Thacker, P. Ji, Z. Lin, A. Urban, W. Lin, Phenanthroline-based metal-organic frameworks for Fe-catalyzed $\mathrm{C}_{\mathrm{sp} 3}-\mathrm{H}$ amination, Faraday Discuss., 201 (2017) 303-315.

[10] M.I. Gonzalez, J. Oktawiec, J.R. Long, Ethylene oligomerization in metal-organic frameworks bearing nickel(ii) 2,2[prime or minute]-bipyridine complexes, Faraday Discuss., 201 (2017) 351-367.

[11] T. Toyao, K. Miyahara, M. Fujiwaki, T.H. Kim, S. Dohshi, Y. Horiuchi, M. Matsuoka, Immobilization of $\mathrm{Cu}$ Complex into $\mathrm{Zr}$-Based MOF with Bipyridine Units for Heterogeneous Selective Oxidation, J. Phys. Chem. C, 119 (2015) 8131-8137.

[12] L. Braglia, E. Borfecchia, L. Maddalena, S. Øien, K.A. Lomachenko, A.L. Bugaev, S. Bordiga, A.V. Soldatov, K.P. Lillerud, C. Lamberti, Exploring structure and reactivity of $\mathrm{Cu}$ sites in functionalized UiO-67 MOFs, Catal. Today, 283 (2017) 89-103.

[13] L. Braglia, E. Borfecchia, K.A. Lomachenko, A.L. Bugaev, A.A. Guda, A.V. Soldatov, B.T.L. Bleken, S. Oien, U. Olsbye, K.P. Lillerud, S. Bordiga, G. Agostini, M. Manzoli, C. Lamberti, Tuning $\mathrm{Pt}$ and $\mathrm{Cu}$ sites population inside functionalized UiO-67 MOF by controlling activation conditions, Faraday Discuss., 201 (2017) 265-286.

[14] C. Wang, Z.G. Xie, K.E. deKrafft, W.L. Lin, Doping metal-organic frameworks for water oxidation, carbon dioxide reduction, and organic photocatalysis, J. Am. Chem. Soc., 133 (2011) 13445-13454.

[15] C.H. Hendon, J. Bonnefoy, E.A. Quadrelli, J. Canivet, M.B. Chambers, G. Rousse, A. Walsh, M. Fontecave, C. Mellot-Draznieks, A simple and non-destructive method for assessing the incorporation of bipyridine dicarboxylates as linkers within metal-organic frameworks, Chem. Eur. J., 22 (2016) 3713-3718.

[16] S. Øien, G. Agostini, S. Svelle, E. Borfecchia, K.A. Lomachenko, L. Mino, E. Gallo, S. Bordiga, U. Olsbye, K.P. Lillerud, C. Lamberti, Probing reactive platinum sites in UiO-67 zirconium metal-organic frameworks, Chem. Mater., 27 (2015) 1042-1056.

[17] T. Toyao, M. Saito, S. Dohshi, K. Mochizuki, M. Iwata, H. Higashimura, Y. Horiuchi, M. Matsuoka, Construction of Pt complex within Zr-based MOF and its application for hydrogen production under visible-light irradiation, Res. Chem. Intermed., 42 (2016) 7679-7688. 
[18] E. Borfecchia, S. Øien, S. Svelle, L. Mino, L. Braglia, G. Agostini, E. Gallo, K. Lomachenko, S. Bordiga, A. Guda, S.M. A., A.V. Soldatov, U. Olsbye, K.P. Lillerud, C. Lamberti, A XAFS study of the local environment and reactivity of Pt-sites in functionalized UiO-67 MOFs, J. Phys. Conf. Ser., 712 (2016) 012125.

[19] L. Braglia, E. Borfecchia, A. Martini, A.L. Bugaev, A.V. Soldatov, S. Oien-Odegaard, B.T. Lonstad-Bleken, U. Olsbye, K.P. Lillerud, K.A. Lomachenko, G. Agostini, M. Manzoli, C. Lamberti, The duality of UiO-67-Pt MOFs: connecting treatment conditions and encapsulated Pt species by operando XAS, Phys. Chem. Chem. Phys., 19 (2017) 27489-27507.

[20] E.S. Gutterød, S. Øien-Ødegaard, K. Bossers, A.-E. Nieuwelink, M. Manzoli, L. Braglia, A. Lazzarini, E. Borfecchia, S. Ahmadigoltapeh, B. Bouchevreau, B.T. Lønstad-Bleken, R. Henry, C. Lamberti, S. Bordiga, B.M. Weckhuysen, K.P. Lillerud, U. Olsbye, CO2 Hydrogenation over Pt-Containing UiO-67 Zr-MOFs - The Base Case, Industrial \& Engineering Chemistry Research, 56 (2017) 13206-13218.

[21] H.H. Fei, S.M. Cohen, A robust, catalytic metal-organic framework with open 2,2 'bipyridine sites, Chem. Commun., 50 (2014) 4810-4812.

[22] L.Y. Chen, X.D. Chen, H.L. Liu, C.H. Bai, Y.W. Li, One-step encapsulation of Pd nanoparticles in MOFs via a temperature control program, J. Mater. Chem. A, 3 (2015) 1525915264.

[23] A.L. Bugaev, A.A. Guda, K.A. Lomachenko, E.G. Kamyshova, M.A. Soldatov, G. Kaur, S. Oien-Odegaard, L. Braglia, A. Lazzarini, M. Manzoli, S. Bordiga, U. Olsbye, K.P. Lillerud, A.V. Soldatov, C. Lamberti, Operando study of palladium nanoparticles inside UiO-67 MOF for catalytic hydrogenation of hydrocarbons, Faraday Discuss., 208 (2018) 287-306.

[24] A. Filipponi, A. Di Cicco, C.R. Natoli, X-ray-absorption spectroscopy andn-body distribution functions in condensed matter. I. Theory, Phys. Rev. B, 52 (1995) 15122-15134.

[25] J.J. Rehr, R.C. Albers, Theoretical approaches to X-ray absorption fine structure, Rev. Mod. Phys., 72 (2000) 621-654.

[26] J.A. van Bokhoven, C. Lamberti, X-ray absorption and X-ray emission spectroscopy: Theory and applications, John Wiley \& Sons, Chichester (UK), 2016.

[27] S. Bordiga, F. Bonino, K.P. Lillerud, C. Lamberti, X-ray absorption spectroscopies: useful tools to understand metallorganic frameworks structure and reactivity, Chem. Soc. Rev., 39 (2010) 4885-4927.

[28] S. Bordiga, E. Groppo, G. Agostini, J.A. van Bokhoven, C. Lamberti, Reactivity of surface species in heterogeneous catalysts probed by in situ X-ray absorption techniques, Chem. Rev., 113 (2013) 1736-1850.

[29] E. Borfecchia, L. Braglia, F. Bonino, S. Bordiga, S. Øien, U. Olsbye, K.P. Lillerud, J.A. van Bokhoven, K.A. Lomachenko, A.A. Guda, M.A. Soldatov, C. Lamberti, Probing structure and reactivity of metal centers in metal-organic frameworks by XAS techniques, in: XAFS Techniques for Catalysts, Nanomaterials, and Surfaces, 2017, pp. 397-430. 
[30] M.A. Soldatov, A. Martini, A.L. Bugaev, I. Pankin, P.V. Medvedev, A.A. Guda, A.M. Aboraia, Y.S. Podkovyrina, A.P. Budnyk, A.A. Soldatov, C. Lamberti, The insights from X-ray absorption spectroscopy into the local atomic structure and chemical bonding of metal-organic frameworks, Polyhedron, 155 (2018) 232-253.

[31] S. Smolders, K.A. Lomachenko, B. Bueken, A. Struyf, A.L. Bugaev, C. Atzori, N. Stock, C. Lamberti, M.B.J. Roeffaers, D. De Vos, Unravelling the redox-catalytic behavior of $\mathrm{Ce}^{4+}$-MOFs: a XAS study, ChemPhysChem, 19 (2018) 373-378.

[32] E. Gallo, E. Gorelov, A.A. Guda, A.L. Bugaev, F. Bonino, E. Borfecchia, G. Ricchiardi, D. Gianolio, S. Chavan, C. Lamberti, Effect of molecular guest binding on the d-d transitions of $\mathrm{Ni}^{2+}$ of CPO-27-Ni: A combined UV-Vis, resonant-valence-to-core X-ray emission spectroscopy, and theoretical study, Inorg. Chem., 56 (2017) 14408-14425.

[33] V.V. Butova, A.P. Budnyk, A.A. Guda, K.A. Lomachenko, A.L. Bugaev, A.V. Soldatov, S.M. Chavan, S. Øien-Ødegaard, U. Olsbye, K.P. Lillerud, C. Atzori, S. Bordiga, C. Lamberti, Modulator effect in UiO-66-NDC (1,4-naphthalenedicarboxylic acid) synthesis and comparison with UiO-67-NDC isoreticular metal-organic frameworks, Cryst. Growth Des., 17 (2017) 54225431.

[34] L. Braglia, E. Borfecchia, K.A. Lomachenko, A.L. Bugaev, A.A. Guda, A.V. Soldatov, B.T.L. Bleken, S. Oien-Odegaard, U. Olsbye, K.P. Lillerud, S. Bordiga, G. Agostini, M. Manzoli, C. Lamberti, Tuning Pt and $\mathrm{Cu}$ sites population inside functionalized UiO-67 MOF by controlling activation conditions, Faraday Discuss., 201 (2017) 277-298.

[35] C. Prestipino, L. Regli, J.G. Vitillo, F. Bonino, A. Damin, C. Lamberti, A. Zecchina, P.L. Solari, K.O. Kongshaug, S. Bordiga, Local structure of framework $\mathrm{Cu}$ (II) in HKUST-1 metallorganic framework: Spectroscopic characterization upon activation and interaction with adsorbates, Chem. Mater., 18 (2006) 1337-1346.

[36] N. Masciocchi, S. Galli, V. Colombo, A. Maspero, G. Palmisano, B. Seyyedi, C. Lamberti, $\mathrm{S}$. Bordiga, Cubic octanuclear Ni(II) clusters in highly porous polypyrazolyl-based materials, J. Am. Chem. Soc., 132 (2010) 7902-7904.

[37] S. Chavan, J.G. Vitillo, E. Groppo, F. Bonino, C. Lamberti, P.D.C. Dietzel, S. Bordiga, CO adsorption on CPO-27-Ni coordination polymer: Spectroscopic features and interaction energy, J. Phys. Chem. C, 113 (2009) 3292-3299.

[38] L. Valenzano, J.G. Vitillo, S. Chavan, B. Civalleri, F. Bonino, S. Bordiga, C. Lamberti, Structure-activity relationships of simple molecules adsorbed on CPO-27-Ni metal-organic framework: In situ experiments vs. theory, Catal. Today, 182 (2012) 67-79.

[39] A.A. Guda, S.A. Guda, M.A. Soldatov, K.A. Lomachenko, A.L. Bugaev, C. Lamberti, W. Gawelda, C. Bressler, G. Smolentsev, A.V. Soldatov, Y. Joly, Finite difference method accelerated with sparse solvers for structural analysis of the metal-organic complexes, J. Phys. Conf. Ser., 712 (2016) Art. n. 012004. 
[40] S.A. Guda, A.A. Guda, M.A. Soldatov, K.A. Lomachenko, A.L. Bugaev, C. Lamberti, W. Gawelda, C. Bressler, G. Smolentsev, A.V. Soldatov, Y. Joly, Optimized finite difference method for the full-potential XANES simulations: Application to molecular adsorption geometries in MOFs and metal-ligand intersystem crossing transients, J. Chem. Theory Comput., 11 (2015) 4512-4521.

[41] E. Borfecchia, S. Maurelli, D. Gianolio, E. Groppo, M. Chiesa, F. Bonino, C. Lamberti, Insights into adsorption of $\mathrm{NH}_{3}$ on HKUST-1 metal-organic framework: A multitechnique approach, J. Phys. Chem. C, 116 (2012) 19839-19850.

[42] J.J. Rehr, A.L. Ankudinov, Progress in the theory and interpretation of XANES, Coord. Chem. Rev., 249 (2005) 131-140.

[43] D. Gianolio, E. Groppo, J.G. Vitillo, A. Damin, S. Bordiga, A. Zecchina, C. Lamberti, Direct evidence of adsorption induced $\mathrm{Cr}^{\mathrm{II}}$ mobility on the $\mathrm{SiO}_{2}$ surface upon complexation by $\mathrm{CO}$, Chem. Commun., 46 (2010) 976-978.

[44] Y. Joly, S. Grenier, Theory of X-Ray Absorption Near Edge Structure, in: J.A. van Bokhoven, C. Lamberti (Eds.) X-Ray Absorption and X-Ray Emission Spectroscopy: Theory and Applications, John Wiley \& Sons, Chichester (UK), 2016, pp. 73-97.

[45] A.A. Guda, S.A. Guda, K.A. Lomachenko, M.A. Soldatov, I.A. Pankin, A.V. Soldatov, L. Braglia, A.L. Bugaev, A. Martini, M. Signorile, E. Groppo, A. Piovano, E. Borfecchia, C. Lamberti, Quantitative structural determination of active sites from in situ and operando XANES spectra: from standard ab initio simulations to chemometric and machine learning approaches, Catal. Today, in press, doi: 10.1016/j.cattod.2018.1010.1071.

[46] E.G. Kamyshova, A.A. Skorynina, A.L. Bugaev, C. Lamberti, A.V. Soldatov, Formation and growth of Pd nanoparticles in UiO-67 MOF by in situ EXAFS, Radiat. Phys. Chem.

[47] J. Jaumot, R. Gargallo, A. de Juan, R. Tauler, A graphical user-friendly interface for MCRALS: a new tool for multivariate curve resolution in MATLAB, Chemom. Intell. Lab. Syst., 76 (2005) 101-110.

[48] R. Tauler, Multivariate curve resolution applied to second order data, Chemom. Intell. Lab. Syst., 30 (1995) 133-146.

[49] J. Jaumot, A. de Juan, R. Tauler, MCR-ALS GUI 2.0: New features and applications, Chemom. Intell. Lab. Syst., 140 (2015) 1-12.

[50] A. Martini, E. Borfecchia, K.A. Lomachenko, I.A. Pankin, C. Negri, G. Berlier, P. Beato, H. Falsig, S. Bordiga, C. Lamberti, Composition-driven $\mathrm{Cu}$-speciation and reducibility in $\mathrm{Cu}-\mathrm{CHA}$ zeolite catalysts: a multivariate XAS/FTIR approach to complexity, Chem. Sci., 8 (2017) 68366851.

[51] D.K. Pappas, E. Borfecchia, M. Dyballa, I.A. Pankin, K.A. Lomachenko, A. Martini, M. Signorile, S. Teketel, B. Arstad, G. Berlier, C. Lamberti, S. Bordiga, U. Olsbye, K.P. Lillerud, S. Svelle, P. Beato, Methane to Methanol: Structure-Activity Relationships for Cu-CHA, J. Am. Chem. Soc., 139 (2017) 14961-14975. 
[52] A. Martini, E. Alladio, E. Borfecchia, Determining $\mathrm{Cu}-$ speciation in the $\mathrm{Cu}-\mathrm{CHA}$ zeolite catalyst: The potential of multivariate curve resolution analysis of in situ XAS data, Top. Catal., 61 (2018) 1396-1407

[53] B.L. Caetano, V. Briois, S.H. Pulcinelli, F. Meneau, C.V. Santilli, Revisiting the ZnO Q-dot formation toward an integrated growth model: From coupled time resolved UV-Vis/SAXS/XAS data to multivariate analysis, J. Phys. Chem. C, 121 (2016) 886-895.

[54] W.H. Cassinelli, L. Martins, A.R. Passos, S.H. Pulcinelli, C.V. Santilli, A. Rochet, V. Briois, Multivariate curve resolution analysis applied to time-resolved synchrotron X-ray absorption spectroscopy monitoring of the activation of copper alumina catalyst, Catal. Today, 229 (2014) 114-122.

[55] J.P. Hong, E. Marceau, A.Y. Khodakov, L. Gaberova, A. Griboval-Constant, J.S. Girardon, C. La Fontaine, V. Briois, Speciation of ruthenium as a reduction promoter of silica-supported Co catalysts: A time-resolved in situ XAS investigation, ACS Catal., 5 (2015) 1273-1282.

[56] A. Rochet, B. Baubet, V. Moizan, E. Devers, A. Hugon, C. Pichon, E. Payen, V. Briois, Intermediate species revealed during sulfidation of bimetallic hydrotreating catalyst: A multivariate analysis of combined time-resolved spectroscopies, J. Phys. Chem. C, 121 (2017) 18544-18556.

[57] D.K. Pappas, A. Martini, M. Dyballa, K. Kvande, S. Teketel, K.A. Lomachenko, R. Baran, P. Glatzel, B. Arstad, G. Berlier, C. Lamberti, S. Bordiga, U. Olsbye, S. Svelle, P. Beato, E. Borfecchia, The Nuclearity of the Active Site for Methane to Methanol Conversion in $\mathrm{Cu}-$ Mordenite: A Quantitative Assessment, Journal of the American Chemical Society, 140 (2018) 15270-15278.

[58] W. van Beek, O.V. Safonova, G. Wiker, H. Emerich, SNBL, a dedicated beamline for combined in situ X-ray diffraction, X-ray absorption and Raman scattering experiments, Phase Transit., 84 (2011) 726-732.

[59] O. Mathon, A. Beteva, J. Borrel, D. Bugnazet, S. Gatla, R. Hino, I. Kantor, T. Mairs, M. Munoz, S. Pasternak, F. Perrin, S. Pascarelli, The time-resolved and extreme conditions XAS (TEXAS) facility at the European Synchrotron Radiation Facility: the general-purpose EXAFS bending-magnet beamline BM23, J. Synchrotron Radiat., 22 (2015) 1548-1554.

[60] D. Bellet, B. Gorges, A. Dallery, P. Bernard, E. Pereiro, J. Baruchel, A $1300 \mathrm{~K}$ furnace for in situ X-ray microtomography, J. Appl. Cryst., 36 (2003) 366-367.

[61] C. Lamberti, S. Bordiga, F. Bonino, C. Prestipino, G. Berlier, L. Capello, F. D'Acapito, F.X.L.I. Xamena, A. Zecchina, Determination of the oxidation and coordination state of copper on different $\mathrm{Cu}$-based catalysts by XANES spectroscopy in situ or in operando conditions, Phys. Chem. Chem. Phys., 5 (2003) 4502-4509.

[62] A.L. Bugaev, A.A. Guda, K.A. Lomachenko, V.V. Shapovalov, A. Lazzarini, J.G. Vitillo, L.A. Bugaev, E. Groppo, R. Pellegrini, A.V. Soldatov, J.A. van Bokhoven, C. Lamberti, Core- 
shell structure of palladium hydride nanoparticles revealed by combined X-ray absorption spectroscopy and X-ray diffraction, J. Phys. Chem. C, 121 (2017) 18202-18213.

[63] A.L. Bugaev, O.A. Usoltsev, A. Lazzarini, K.A. Lomachenko, A.A. Guda, R. Pellegrini, M. Carosso, J.G. Vitillo, E. Groppo, J. van Bokhoven, A.V. Soldatov, C. Lamberti, Time-resolved operando studies of carbon supported Pd nanoparticles under hydrogenation reactions by X-ray diffraction and absorption, Faraday Discuss., 208 (2018) 187-205.

[64] J. Kieffer, D. Karkoulis, PyFAI, a versatile library for azimuthal regrouping, J. Phys. Conf. Ser., 425 (2013).

[65] V. Petříček, M. Dušek, L. Palatinus, Crystallographic computing system JANA2006: General features, Z. Kristallogr. Cryst. Mater., 229 (2014).

[66] T. Ressler, J. Wong, J. Roos, I.L. Smith, Quantitative speciation of Mn-bearing particulates emitted from autos burning (methylcyclopentadienyl)manganese tricarbonyl-added gasolines using XANES spectroscopy, Environ. Sci. Technol., 34 (2000) 950-958.

[67] D. Bazin, J.J. Rehr, Limits and advantages of x-ray absorption near edge structure for nanometer scale metallic clusters, J. Phys. Chem. B, 107 (2003) 12398-12402.

[68] A. Piovano, G. Agostini, A.I. Frenkel, T. Bertier, C. Prestipino, M. Ceretti, W. Paulus, C. Lamberti, Time resolved in situ XAFS study of the electrochemical oxygen intercalation in $\mathrm{SrFeO}_{2.5}$ brownmillerite structure: Comparison with the homologous $\mathrm{SrCoO}_{2.5}$ system, J. Phys. Chem. C, 115 (2011) 1311-1322.

[69] M. Ferrandon, A.J. Kropf, D.J. Myers, K. Artyushkova, U. Kramm, P. Bogdanoff, G. Wu, C.M. Johnston, P. Zelenay, Multitechnique characterization of a polyaniline-iron-carbon oxygen reduction catalyst, J. Phys. Chem. C, 116 (2012) 16001-16013.

[70] A.L. Bugaev, A.A. Guda, I.A. Pankin, E. Groppo, R. Pellegrini, A. Longo, A.V. Soldatov, C. Lamberti, The role of palladium carbides in the catalytic hydrogenation of ethylene over supported palladium nanoparticles, Catal. Today, submitted to this volume.

[71] O. Bunau, Y. Joly, Self-consistent aspects of X-ray absorption calculations, J. Phys. Condens. Matter, 21 (2009) Art. n. 345501.

[72] G. Kresse, J. Furthmuller, Efficient iterative schemes for ab initio total-energy calculations using a plane-wave basis set, Phys. Rev. B, 54 (1996) 11169-11186.

[73] G. Kresse, D. Joubert, From ultrasoft pseudopotentials to the projector augmented-wave method, Phys. Rev. B, 59 (1999) 1758-1775.

[74] J. Hafner, Ab-initio simulations of materials using VASP: Density-functional theory and beyond, J. Comput. Chem., 29 (2008) 2044-2078.

[75] J.P. Perdew, K. Burke, M. Ernzerhof, Generalized gradient approximation made simple, Phys. Rev. Lett., 77 (1996) 3865-3868. 